\title{
Article \\ Facile Synthesis and Characterization of Palladium@Carbon Catalyst for the Suzuki-Miyaura and Mizoroki-Heck Coupling Reactions
}

\author{
Hamed M. Alshammari ${ }^{1}{ }^{(\mathbb{C},}$, Obaid F. Aldosari ${ }^{2, *} \mathbb{0}$, Mohammad Hayal Alotaibi ${ }^{3, *} \mathbb{0}$, Raja L. Alotaibi ${ }^{3}$, \\ Mosaed S. Alhumaimess ${ }^{4}$, Moataz H. Morad ${ }^{5}$, Syed Farooq Adil ${ }^{6, *}{ }^{(\mathbb{D}}$, Mohammed Rafi Shaik ${ }^{6} \mathbb{D}_{\text {, }}$ \\ Mohammad Shahidul Islam ${ }^{6}(\mathbb{D})$, Mujeeb Khan ${ }^{6}$ id and Abdulrahman Alwarthan ${ }^{6}$ \\ Citation: Alshammari, H.M.; \\ Aldosari, O.F.; Alotaibi, M.H.; \\ 1 Chemistry Department, Faculty of Science, Ha'il University, P.O. Box 2440, Ha'il 81451, Saudi Arabia; \\ h.alshammari@uoh.edu.sa \\ 2 Department of Chemistry, College of Science, Majmaah University, P.O. Box 66, Majmaah 11952, Saudi Arabia \\ 3 National Center for Petrochemicals Technology, King Abdulaziz City for Science and Technology (KACST), \\ P.O. Box 6086, Riyadh 11442, Saudi Arabia; raletabi@kacst.edu.sa \\ 4 Chemistry Department, College of Science, Jouf University, P.O. Box 2014, Sakaka 72351, Saudi Arabia; \\ mosaed@ju.edu.sa \\ 5 Chemistry Department, Faculty of Applied Sciences, Umm Al-Qura University, Makkah 21955, Saudi Arabia; \\ mhmorad@uqu.edu.sa \\ 6 Department of Chemistry, College of Science, King Saud University, P.O. Box 2455, \\ Riyadh 11451, Saudi Arabia; mrshaik@ksu.edu.sa (M.R.S.); mislam@ksu.edu.sa (M.S.I.); \\ kmujeeb@ksu.edu.sa (M.K.); awarthan@ksu.edu.sa (A.A.) \\ * Correspondence: o.aldosari@mu.edu.sa (O.F.A.); mhhalotaibi@kacst.edu.sa (M.H.A.); \\ sfadil@ksu.edu.sa (S.F.A.); Tel.: +966-11-4670439 (S.F.A.)
} Alotaibi, R.L.; Alhumaimess, M.S.; Morad, M.H.; Adil, S.F.; Shaik, M.R.; Islam, M.S.; Khan, M.; et al. Facile Synthesis and Characterization of Palladium@Carbon Catalyst for the Suzuki-Miyaura and Mizoroki-Heck Coupling Reactions. Appl. Sci. 2021, 11, 4822. https://doi.org/10.3390/ app11114822

Academic Editor: Nicola Cioffi

Received: 4 March 2021

Accepted: 20 May 2021

Published: 24 May 2021

Publisher's Note: MDPI stays neutral with regard to jurisdictional claims in published maps and institutional affiliations.

Copyright: (c) 2021 by the authors. Licensee MDPI, Basel, Switzerland. This article is an open access article distributed under the terms and conditions of the Creative Commons Attribution (CC BY) license (https:/ / creativecommons.org/licenses/by/ $4.0 /)$.
Abstract: Palladium-based carbon catalysts (Pd/C) can be potentially applied as an efficient catalyst for Suzuki-Miyaura and Mizoroki-Heck coupling reactions. Herein, a variety of catalysts of palladium on activated carbon were prepared by varying the content of ' $\mathrm{Pd}$ ' via an in situ reduction method, using hydrogen as a reducing agent. The as-prepared catalysts $(0.5 \mathrm{wt} \% \mathrm{Pd} / \mathrm{C}, 1 \mathrm{wt} \% \mathrm{Pd} / \mathrm{C}$, $2 \mathrm{wt} \% \mathrm{Pd} / \mathrm{C}$ and $3 \mathrm{wt} \% \mathrm{Pd} / \mathrm{C}$ ) were characterized using X-ray diffraction (XRD), scanning electron microscopy (SEM), energy dispersive X-ray spectroscopy (EDX) and Brunauer-Emmett-Teller (BET) analyses. The catalysts were tested as a coupling catalyst for Suzuki-Miyaura coupling reactions involving aryl halides and phenyl boronic acid. The optimization of the catalyst by varying the palladium content on the activated carbon yielded $\mathrm{Pd} / \mathrm{C}$ catalysts with very high catalytic activity for Suzuki reactions of aryl halides and a Mizoroki-Heck cross-coupling reaction of 4-bromoanisol and acrylic acid in an aqueous medium. A high ' $\mathrm{Pd}$ ' content and uniform ' $\mathrm{Pd}$ ' impregnation significantly affected the activity of the catalysts. The catalytic activity of $3 \% \mathrm{Pd} / \mathrm{C}$ was found to make it a more efficient catalyst when compared with the other synthesized Pd/C catalysts. Furthermore, the catalyst reusability was also tested for Suzuki reactions by repeatedly performing the same reaction using the recovered catalyst. The $3 \% \mathrm{Pd} / \mathrm{C}$ catalyst displayed better reusability even after several reactions.

Keywords: palladium; carbon; catalyst; Suzuki-Miyaura coupling; Mizoroki-Heck

\section{Introduction}

Transition metal-facilitated cross-couplings, specifically Suzuki-Miyaura, Sonogashira, Heck, Hiyama, Stille, Negishi and Kumada reactions, are significant tools for C-C bond formation [1-7]. The significance of carbon-carbon bonds in establishing reactions is heavily acknowledged in various fields such as natural and biological products, polymers and particularly in catalysis [8,9]. The industrial significance of Suzuki and Heck couplings, along with several others, has particularly generated considerable advancement in the progress of $\mathrm{C}-\mathrm{C}$ bond reactions. Suzuki-Miyaura couplings have been especially widely 
exploited in recent years $[10,11]$, which potentially offer quick entry to biaryl frameworks via the sp2-sp2 connection [12]. Suzuki-Miyaura and Mizoroki-Heck cross-coupling reactions are extensively applied, owing to their excellent properties such as mild reaction conditions, easy availability of precursors, good stability under aerobic conditions and the use of nonhazardous boronic acids as precursors. So far, reports on the use of several palladium-, nickel- and gold-based compounds as catalysts for cross-coupling reactions have been published [13,14].

Among the various transition metals, Suzuki-Miyaura reactions are usually catalyzed by palladium-based homogenous catalysts that have shown high catalytic activity. However, under homogeneous conditions, catalysts require hazardous ligands like phosphine or other N-heterocyclic compounds [15], and moreover, separating the catalysts after the reaction is cumbersome process. This not only causes contamination of the product but also severely affects the recovery of the catalysts [16-18]. The separation of leached catalysts from the product solution requires the application of costly filtration membranes or other chromatographic techniques. Therefore, tremendous efforts have been made over the years to develop heterogeneous processes with the aim of replacing homogenous systems. Recently, the advancement of nanotechnology has led to the development of highly efficient palladium nanoparticle (Pd NP)-based heterogeneous catalysts $[19,20]$. These catalysts possess excellent catalytic activity due to their remarkable physicochemical properties (high surface area) and are successfully used as replacements for the conventional organometallic-based compounds for Suzuki-Miyaura coupling reactions [10,21-24].

Currently, 'Pd' is considered the most exciting heterogeneous catalyst in coupling reactions due to its size, shape and other catalytic activities [25-27]. Among various reactions, the palladium-catalyzed coupling reactions involving aryl halides and phenyl/aryl boronic acids are considered the most beneficial approaches for the development of biaryl units, which are highly useful as intermediates in numerous pharmaceuticals and polymers like electroluminescence materials [28]. However, in many cases, the application of Pd NPs has been seriously restricted due to the inefficiency of separation methods like centrifugation and filtration for the recovery of whole nanoparticle-based catalysts [25]. Additionally, NPs are also susceptible to agglomeration under reaction conditions. Therefore, to overcome these issues, supported Pd NPs are preferred for $\mathrm{C}-\mathrm{C}$ cross coupling reactions. Thus far, significant efforts have been made toward improving a variety of novel and effective palladium-based supported catalysts for Suzuki-Miyaura coupling reactions [29]. Recently, the synthesis of Pd-based graphene nanocomposites for Suzuki-Miyaura coupling reactions have successfully reported [10,28,30-32].

Besides that, carbon nanotubes have also been developed as competent supports for palladium and applied extensively as catalysts for C-C cross-coupling reactions [33-35]. The carbon nanotubes can be uniformly dispersed in a solution, owing to their small size, thus enhancing the interactions among the reactants and the catalyst [33]. However, the sophisticated synthesis of CNTs and the difficulty in dispersing the nanoparticles on their surfaces seriously hinders their practical applications. Thus, the improvement of simple and efficient approaches for the synthesis of highly active, supported Pd-based nanocatalysts still remains challenging [36].

In this regard, palladium-based carbon support nanocomposite materials have been extensively useful in cross-coupling reactions [37,38]. Nevertheless, $\mathrm{Pd} / \mathrm{C}$ or other heterogeneous, $\mathrm{Pd}$-catalyzed $\mathrm{C}-\mathrm{C}$ couplings are commonly established for the preparation of a variety of organic molecules. Moreover, carbon as a solid support certifies a greater surface area associated with the analogous silica and alumina-supported catalysts [38]. Palladiumbased carbon catalysts are stated to be more stable in air and water, as well as acids and bases, and often do not require reactions to be performed under an inert atmosphere [38]. Indeed, Pd/C-catalyzed Suzuki reactions can be effectively accomplished under diverse reaction conditions, including in aqueous media [39,40], in organic media [41-43] and under microwave circumstances [44-46]. 
Here, we report on palladium on activated carbon catalysts, which were prepared by varying the content of 'Pd' via an in situ reduction method using hydrogen as a reducing agent. The as-prepared various concentrations of the $\mathrm{Pd} / \mathrm{C}$ catalysts were characterized by a number of methods, comprising XRD, SEM, EDX and BET. The as-synthesized $\mathrm{Pd} / \mathrm{C}$ catalysts were applied to Suzuki-Miyaura and Mizoroki-Heck cross-coupling reactions. The synthesized 3\% Pd/C catalyst showed exceptional catalytic efficiency toward the Suzuki-Miyaura and Mizoroki-Heck reactions under facile environments in aqueous conditions.

\section{Materials and Methods}

2.1. Materials

Palladium (II) chloride (99.99\%), chlorobenzene (99.5\%), iodobenzene (99\%), bromobenzene (99.5\%), 4-bromoanisol (99.5\%), acrylic acid (99\%), sodium dodecyl sulfate $(98 \%)$, phenyl boronic acid (95\%), tripotassium phosphate (98\%) and all organic solvents were procured from Sigma-Aldrich, St. Louis, MO, USA.

\subsection{Methods}

\subsubsection{Catalyst Preparation}

Pd loaded on activated carbon, designated Pd/C, was made by stirring activated carbon powder with a stoichiometric amount (wt \%) of palladium (II) chloride (Sigma Aldrich) together in water at $80{ }^{\circ} \mathrm{C}$ for $24 \mathrm{~h}$, followed by filtration and washing using distilled water. Then, the sample was dried at $100^{\circ} \mathrm{C}$, and the sample was reduced by a hydrogen flow at $250{ }^{\circ} \mathrm{C}$ for $2 \mathrm{~h}$.

\subsubsection{Suzuki-Miyaura Reaction Catalyzed by a Pd/C Nanocatalyst}

The Suzuki-Miyaura coupling reaction procedure is provided in the Supplementary Materials.

\subsection{Mizoroki-Heck Cross-Coupling Reaction}

In an air-tied screw-capped vial $(10 \mathrm{~mL})$, a $3 \% \mathrm{Pd} / \mathrm{C}(10 \mathrm{mg})$ catalyst, $\mathrm{K}_{3} \mathrm{PO}_{4}(424 \mathrm{mg}$, $2.0 \mathrm{mmol})$, SDS (288 mg, $1.0 \mathrm{mmol})$ and water $(4 \mathrm{~mL})$ were charged with a small magnetic stir bar. Then, aryl halides $(1.1 \mathrm{mmol})$ were added to it, followed by acrylic acid $(72 \mathrm{mg}$, $1.0 \mathrm{mmol}$ ). The reaction was left stirring at $100{ }^{\circ} \mathrm{C}$ for $10 \mathrm{~h}$. Then, the vial was cooled to room temperature. The reaction mass was basified with aqueous $\mathrm{K}_{2} \mathrm{CO}_{3}(4 \mathrm{M}, 4 \mathrm{~mL})$, followed by being washed with ethyl acetate $(2 \times 2 \mathrm{~mL})$. Then, the aqueous layer was again acidified with $\mathrm{HCl}(4 \mathrm{M}, \mathrm{PH}=1-2)$, and the product was extracted in ethyl acetate $(3 \times 5 \mathrm{~mL})$. The combined ethyl acetate was dried over anhydrous $\mathrm{Mg}_{2} \mathrm{SO}_{4}$. The organic layer was concentrated under reduced pressure to afford pure compounds $3 \mathbf{a}-\mathbf{e}$. All the products were characterized by ${ }^{1} \mathrm{H}-\mathrm{NMR}$ and ${ }^{13} \mathrm{C}-\mathrm{NMR}$ spectra (Supplementary Materials, Figures S1-S10).

\subsection{Characterization}

The characterization and instrumental details are provided in the Supplementary Materials.

\section{Results and Discussion}

\subsection{XRD Analysis}

In the beginning, $\mathrm{XRD}$ was applied to examine the formation and crystallinity of the $\mathrm{Pd} / \mathrm{C}$ catalyst. The first peak at the lower Bragg's angle of $24.8^{\circ}$ was related with the graphite (200) plane of the activated carbon support as shown in Figure 1. For the Pd/C catalyst, the typical diffraction peaked at $40.1^{\circ}(111), 46.5^{\circ}(200), 68.3^{\circ}(220), 81.7^{\circ}(311)$ or $86.4^{\circ}(222)$, corresponding to the face-centered cubic crystalline structure. This confirmed the successful deposition of $\mathrm{Pd}$ on the surface of the activated carbon. 


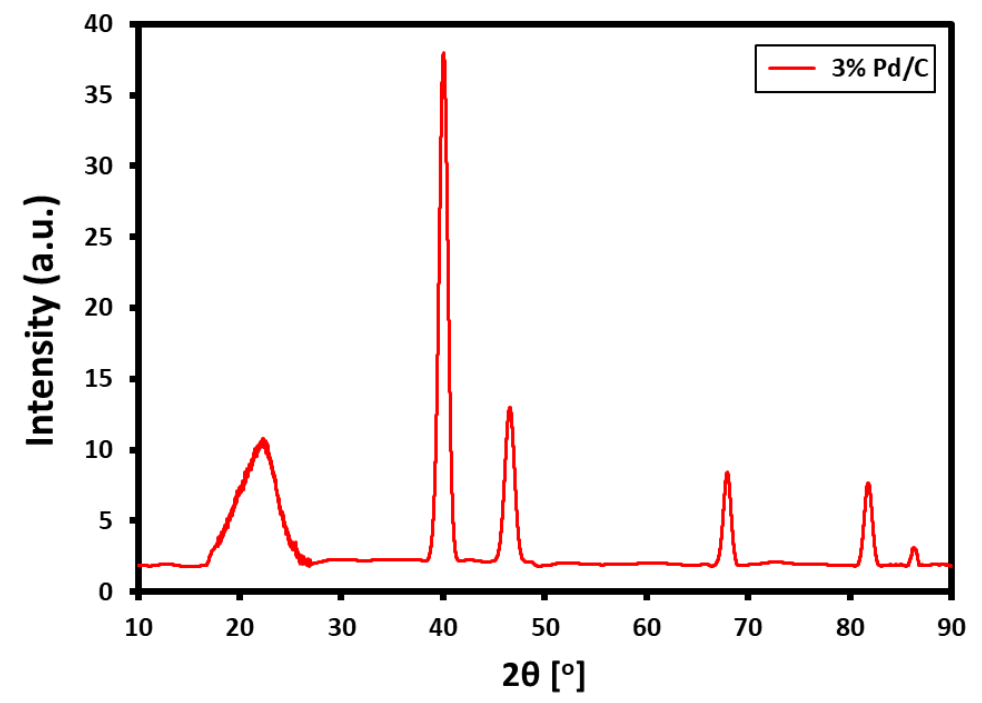

Figure 1. XRD analysis of $3 \% \mathrm{Pd} / \mathrm{C}$.

\subsection{SEM and EDX Analysis}

The texture of the as-prepared Pd/C catalyst was scrutinized by SEM analysis (Figure 2), and it was found that the catalysts prepared were found to possess a rugged, undefined morphology, and there was no effect when increasing the Pd upon the carbon support. The images obtained are given in Figure 3. The percentage of composition of Pd in the catalytic system was confirmed by EDX studies, which revealed that the Pd \% in the $3 \% \mathrm{Pd} / \mathrm{C}$ catalyst contained $2.88 \% \mathrm{Pd}$, which was close to the theoretical percentage.
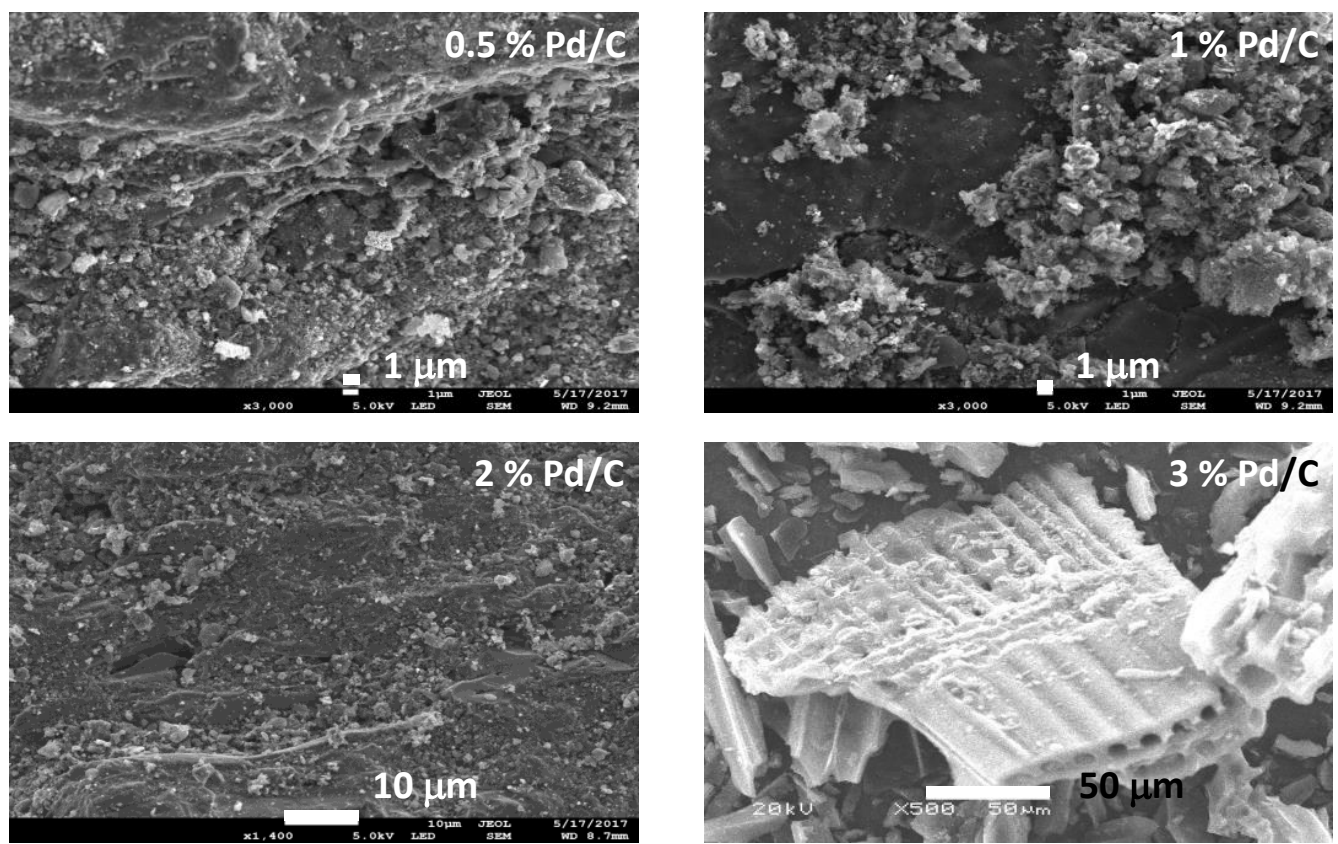

Figure 2. SEM images of the $0.5 \%, 1 \%, 2 \%$ and $3 \% \mathrm{Pd} / \mathrm{C}$ catalysts. 


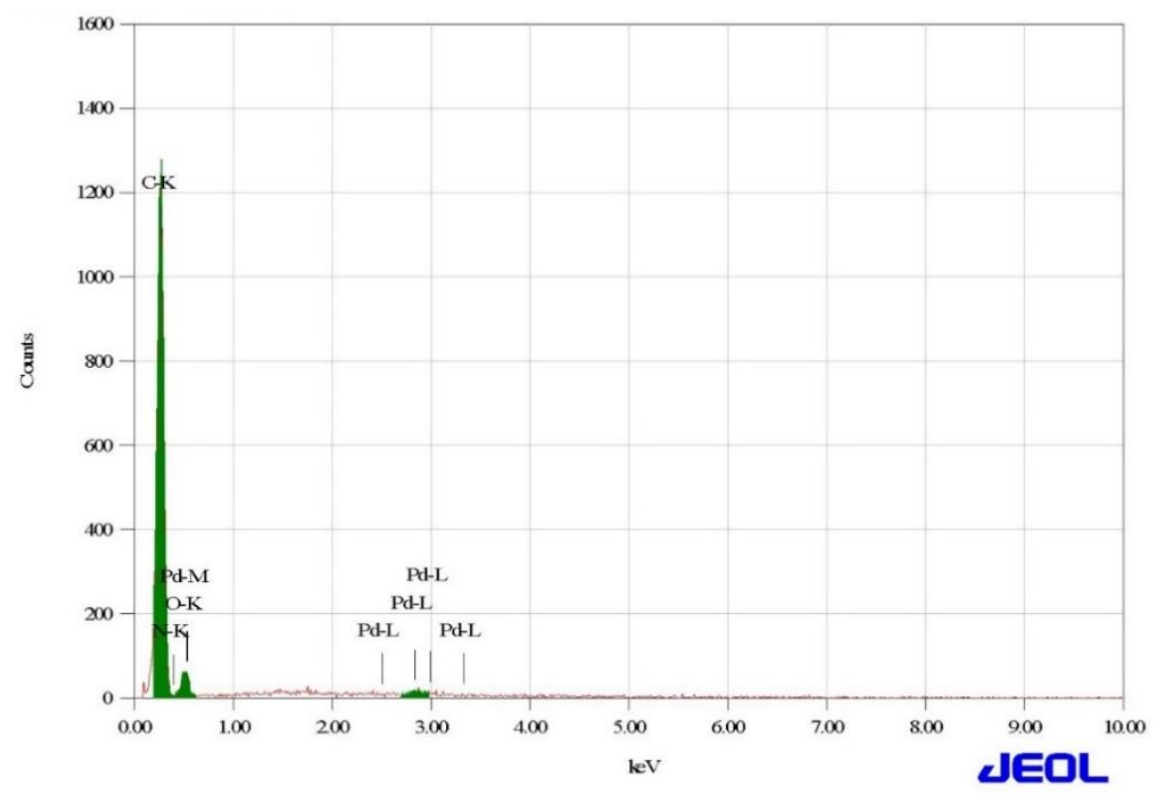

Figure 3. EDX analysis of $3 \% \mathrm{Pd} / \mathrm{C}$.

\subsection{BET Analysis}

The as-prepared $\mathrm{Pd} / \mathrm{C}$ catalysts were studied to evaluate their adsorption profiles, and it was found that all the prepared materials exhibited that, with the increase in the percentage of $\mathrm{Pd}$, the amount of $\mathrm{N}_{2}$ adsorbed increased, indicating enhanced interacting sites with the increase in the Pd percentage (Figure 4). The pore size distribution obtained from the studies revealed that the pore sizes of the $0.5-2 \%$ catalysts were found to be in the range of 200-600 nm, and the pore volume obtained indicated that the pores were deep channels in the range of $0.07-0.08 \mathrm{~cm}^{3} / \mathrm{g}$. The catalyst with $3 \% \mathrm{Pd} / \mathrm{C}$ was found to possess a pore size distribution of $25-150 \mathrm{~nm}$, and the pore volume indicated the formation of shallow pores. Moreover, the BET surface areas of the samples increased with the increasing of Pd content; the $0.5 \%, 1 \%, 2 \%$ and $3 \%$ Pd demonstrated surface areas of 837 , 838,841 and $933 \mathrm{~m}^{2} / \mathrm{g}$, respectively.
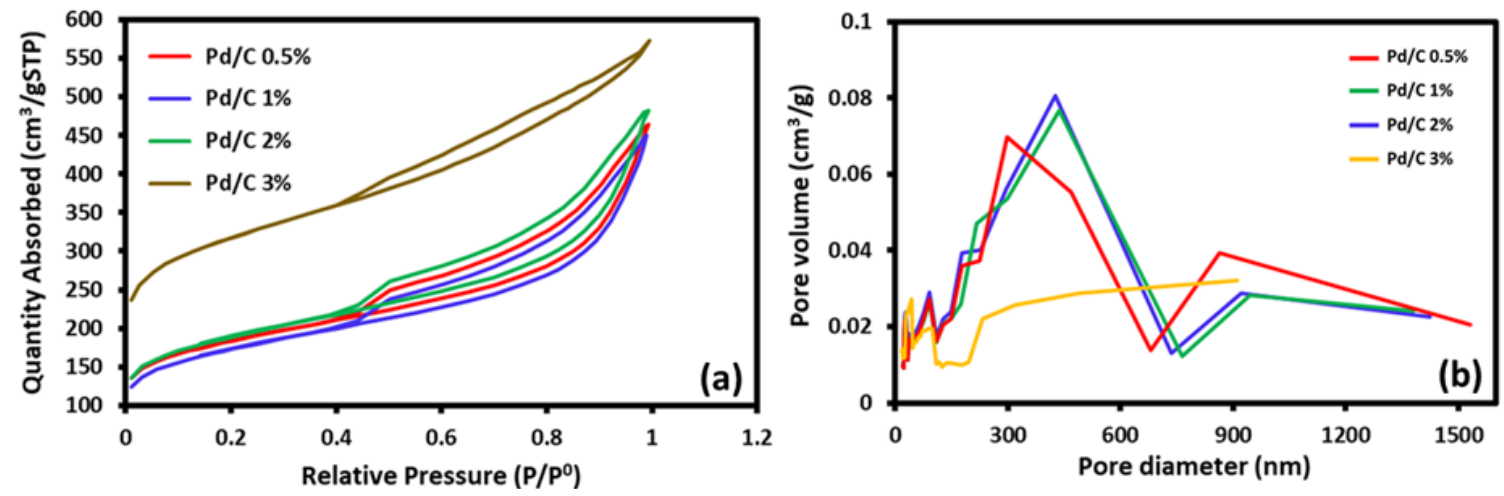

Figure 4. (a) Adsorption-desorption isotherms of the $0.5 \% \mathrm{Pd} / \mathrm{C}, 1 \% \mathrm{Pd} / \mathrm{C}, 2 \% \mathrm{Pd} / \mathrm{C}$ and $3 \% \mathrm{Pd} / \mathrm{C}$ catalysts. (b) Pore size distributions of the $0.5 \% \mathrm{Pd} / \mathrm{C}, 1 \% \mathrm{Pd} / \mathrm{C}, 2 \% \mathrm{Pd} / \mathrm{C}$ and $3 \% \mathrm{Pd} / \mathrm{C}$ catalysts.

\subsection{Suzuki Reaction Catalyzed by the Pd/C Catalyst}

In this study, the Pd/C catalyst was assessed in the Suzuki-Miyaura coupling of halobenzene with phenylboronic acid (Figure 5). S comparison between the catalytic performances of the prepared catalysts (i.e., $0.5 \% \mathrm{Pd} / \mathrm{C}, 1 \% \mathrm{Pd} / \mathrm{C}, 2 \% \mathrm{Pd} / \mathrm{C}$ and $3 \% \mathrm{Pd} / \mathrm{C}$ ) was carried out for the substrate iodobenzene and phenyl boronic acid, and it was found that the amount of Pd in the catalytic system had a significant effect on the catalytic activity 
of the resultant catalyst. Among various catalysts, the 3\% Pd/C yielded a 100\% coupled product within $10 \mathrm{~min}$, while the $1 \% \mathrm{Pd} / \mathrm{C}$ and $2 \% \mathrm{Pd} / \mathrm{C}$ catalysts yielded $100 \%$ coupled products within $20 \mathrm{~min}$ and $15 \mathrm{~min}$, respectively. However, the $0.5 \% \mathrm{Pd} / \mathrm{C}$ catalyst yielded a $\sim 80 \%$ coupled product in $60 \mathrm{~min}$. The outcomes exposed that the iodo-substituted aryl compound yielded a $100 \%$ coupled product at the fastest reaction rate within $10 \mathrm{~min}$ when the $3 \% \mathrm{Pd} / \mathrm{C}$ catalyst was employed. However, when the same catalyst was used for the coupling of bromo- and chloro-substituted aryl substrates, it yielded a 100\% coupled product within $40 \mathrm{~min}$ and $\sim 85 \%$ within $150 \mathrm{~min}$, respectively. The difference in the rate of the reaction can be ascribed to the increasing anionic nature among the halogens down the group. The reaction kinetics was done using the GC, which was scrutinized by accumulating the reaction mixture at equivalent time intervals and quenched straightaway. The data graphical representation is shown in Figure 6.

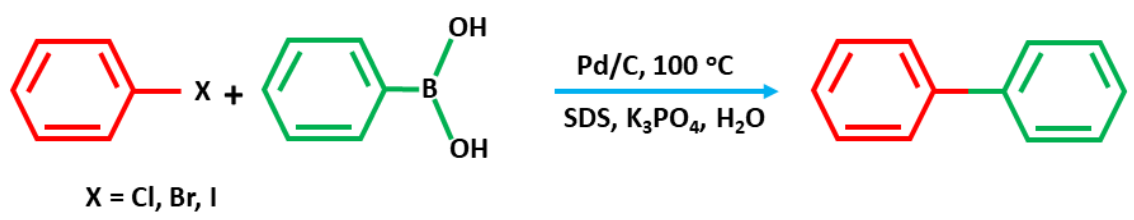

Figure 5. Graphical representation of the Suzuki reaction of iodobenzene, bromobenzene and chlorobenzene with phenylboronic acid under aqueous conditions.
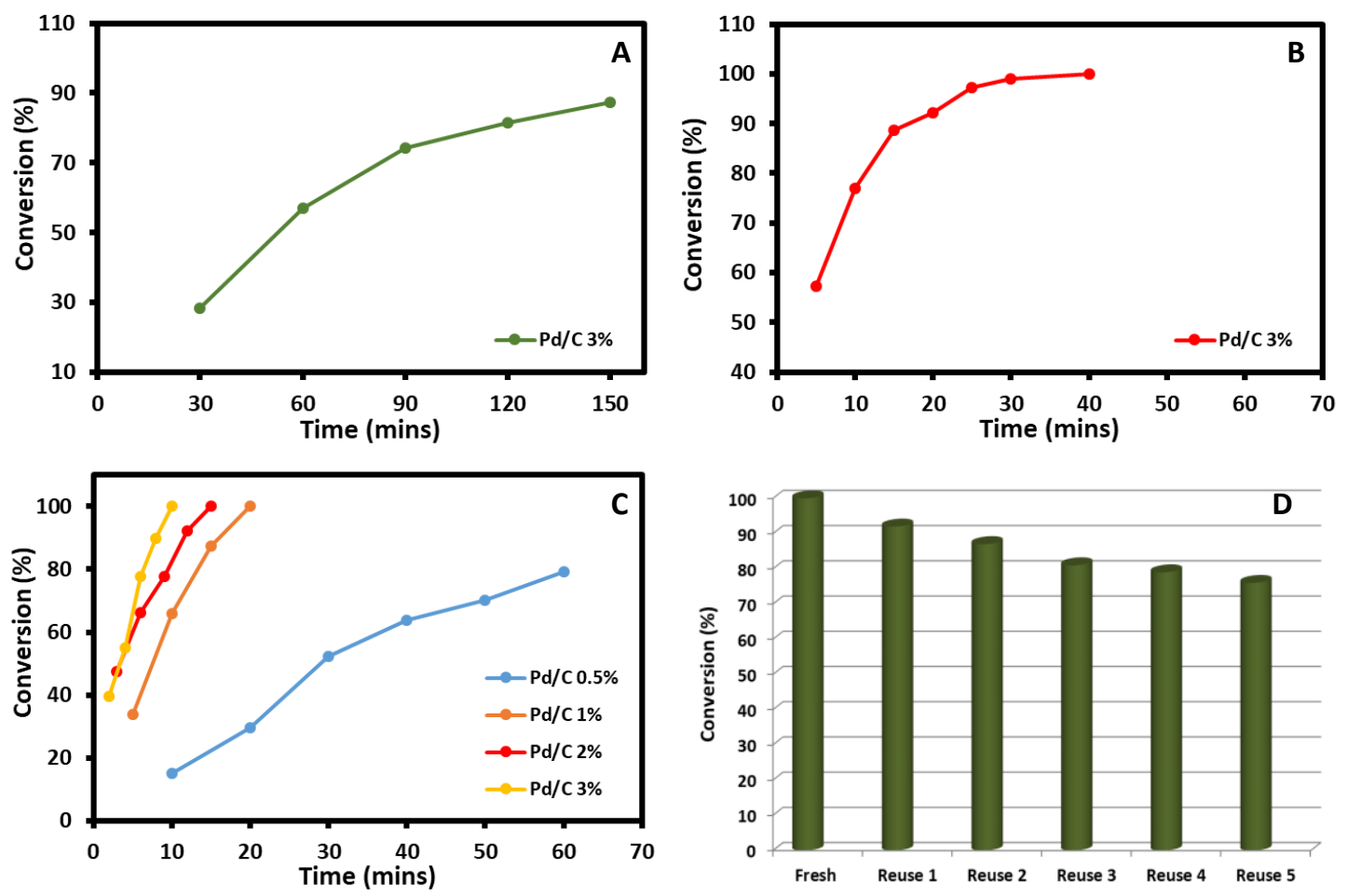

Figure 6. Chemical kinetics plot of the Suzuki reaction using a Pd/C catalyst for various substrates: (A) chlorobenzene, (B) bromobenzene and (C) iodobenzene. (D) Recyclability studies for the Pd/C 3\% catalyst, using iodobenzene as the main reactant.

The as-synthesized $\mathrm{Pd} / \mathrm{C}$ catalysts were evaluated for their reusability to investigate the reduction in the catalytic activity with repeated reuse. The reactions were performed in a similar approach to the aforementioned process. Using iodobenzene as the main reactant, the residual catalyst was collected by centrifugation after the reaction's completion. The catalyst was washed away many times with water to exterminate any residual impurities. It was witnessed that there was a reduction in the product percentage formed upon reuse. The product percentage depreciated up to $76 \%$ when used up to 5 times. 


\subsection{Mizoroki-Heck Cross-Coupling Reaction by the Pd/C Catalyst}

The Pd/C catalyst for the Mizoroki-Heck cross-coupling reaction of 4-bromoanisol and acrylic acid in an aqueous medium was optimized as follows (Figure 7).

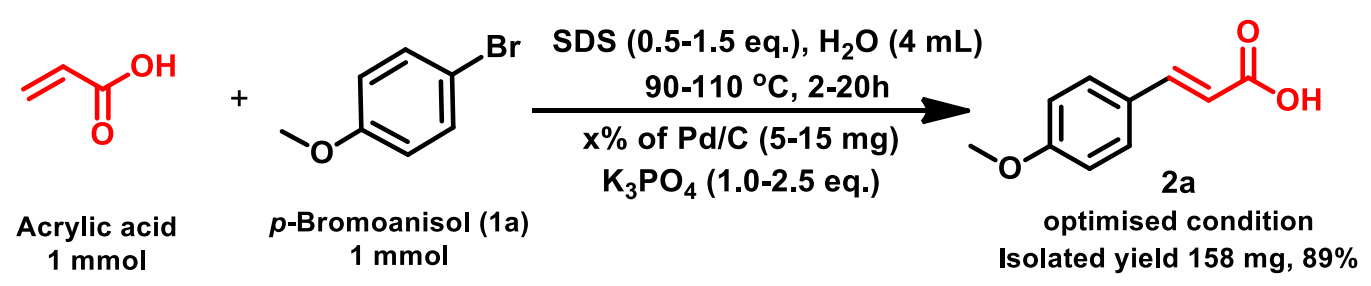

Figure 7. Pd/C-catalyzed MH-C reaction of $p$-bromoanisol (1a) and acrylic acid.

In an air-tied screw-capped vial $(10 \mathrm{~mL})$, an $\mathrm{x} \% \mathrm{Pd} / \mathrm{C}$ catalyst $(5-15 \mathrm{mg}), \mathrm{K}_{3} \mathrm{PO}_{4}$ $(1.0-2.5 \mathrm{mmol})$, SDS $(0.5-1.5 \mathrm{mmol})$ and water $(4 \mathrm{~mL})$ were charged with a small magnetic stir bar. Then, $p$-bromoanisol $1 \mathrm{a}(1.0 \mathrm{mmol})$ was added, followed by acrylic acid $(1.0 \mathrm{mmol})$. The reaction was left stirring at $70-100{ }^{\circ} \mathrm{C}$ for $2-20 \mathrm{~h}$. The reaction was monitored by TLC chromatography and purified by acid-base purification techniques. The findings are reported in Table 1.

Table 1. Mizoroki-Heck reaction optimization of the $\mathrm{Pd} / \mathrm{C}$ catalyst.

\begin{tabular}{cccccccc}
\hline $\begin{array}{c}\text { Sl. } \\
\text { No. }\end{array}$ & Catalyst & $\begin{array}{c}\text { Wt. of } \\
\text { Catalyst }\end{array}$ & $\mathbf{K}_{3} \mathbf{P O}_{\mathbf{4}}$ & SDS & $\begin{array}{c}\text { Temp. } \\
\left({ }^{\circ} \mathbf{C}\right)\end{array}$ & $\begin{array}{c}\text { Time } \\
(\mathbf{h})\end{array}$ & $\begin{array}{c}\text { Isolated } \\
\text { Yield }\end{array}$ \\
\hline 1 & $3.0 \% \mathrm{Pd} / \mathrm{C}$ & $10 \mathrm{mg}$ & 1.0 eq. & - & 100 & $10 \mathrm{~h}$ & No reaction \\
2 & $3.0 \% \mathrm{Pd} / \mathrm{C}$ & $10 \mathrm{mg}$ & 1.0 eq. & 0.5 eq. & 100 & $10 \mathrm{~h}$ & $27 \%$ \\
3 & $3.0 \% \mathrm{Pd} / \mathrm{C}$ & $10 \mathrm{mg}$ & 1.0 eq. & 1.0 eq. & 100 & $10 \mathrm{~h}$ & $46 \%$ \\
4 & $3.0 \% \mathrm{Pd} / \mathrm{C}$ & $10 \mathrm{mg}$ & 1.0 eq. & 1.5 eq. & 100 & $10 \mathrm{~h}$ & $47 \%$ \\
5 & $3.0 \% \mathrm{Pd} / \mathrm{C}$ & $10 \mathrm{mg}$ & 1.5 eq. & 1.0 eq. & 100 & $10 \mathrm{~h}$ & $63 \%$ \\
6 & $3.0 \% \mathrm{Pd} / \mathrm{C}$ & $10 \mathrm{mg}$ & 2.0 eq. & 1.0 eq. & 100 & $10 \mathrm{~h}$ & $89 \%$ \\
7 & $3.0 \% \mathrm{Pd} / \mathrm{C}$ & $15 \mathrm{mg}$ & 2.5 eq. & 1.0 eq. & 100 & $10 \mathrm{~h}$ & $87 \%$ \\
8 & $0.5 \% \mathrm{Pd} / \mathrm{C}$ & $10 \mathrm{mg}$ & 2.0 eq. & 1.0 eq. & 100 & $10 \mathrm{~h}$ & $45 \%$ \\
9 & $1.0 \% \mathrm{Pd} / \mathrm{C}$ & $10 \mathrm{mg}$ & 2.0 eq. & 1.0 eq. & 100 & $10 \mathrm{~h}$ & $57 \%$ \\
10 & $2.0 \% \mathrm{Pd} / \mathrm{C}$ & $10 \mathrm{mg}$ & 2.0 eq. & 1.0 eq. & 100 & $10 \mathrm{~h}$ & $76 \%$ \\
11 & $3.0 \% \mathrm{Pd} / \mathrm{C}$ & $10 \mathrm{mg}$ & 2.0 eq. & 1.0 eq. & 100 & $2 \mathrm{~h}$ & $17 \%$ \\
12 & $3.0 \% \mathrm{Pd} / \mathrm{C}$ & $10 \mathrm{mg}$ & 2.0 eq. & 1.0 eq. & 100 & $5 \mathrm{~h}$ & $34 \%$ \\
13 & $3.0 \% \mathrm{Pd} / \mathrm{C}$ & $10 \mathrm{mg}$ & 2.0 eq. & 1.0 eq. & 100 & $16 \mathrm{~h}$ & $86 \%$ \\
14 & $3.0 \% \mathrm{Pd} / \mathrm{C}$ & $10 \mathrm{mg}$ & 2.0 eq. & 1.0 eq. & 90 & $20 \mathrm{~h}$ & $11 \%$ \\
15 & $3.0 \% \mathrm{Pd} / \mathrm{C}$ & $10 \mathrm{mg}$ & 2.0 eq. & 1.0 eq. & 110 & $20 \mathrm{~h}$ & $83 \%$ \\
\hline
\end{tabular}

The catalytic activity of a newly synthesized Pd/C nanocatalyst for a Mizoroki-Heck cross-coupling reaction in an aqueous medium was tested. The 4-bromoanisol and acrylic acid were taken as the standard substrates for the reaction optimization process (Figure 8). Our initial results are summarized in Table 1 . Initially, the $\mathrm{MH}-\mathrm{C}$ coupling reactions were tried with $10 \mathrm{mg}$ of the $3 \% \mathrm{Pd} / \mathrm{C}$ catalyst and 1 eq. of $\mathrm{K}_{3} \mathrm{PO}_{4}$ in water $(4 \mathrm{~mL})$ at $100{ }^{\circ} \mathrm{C}$ for $10 \mathrm{~h}$. Without the use of sodium dodecyl sulfate, no reaction took place (Table 1, entry 1 ). However, with the use of 0.5 eq. of sodium dodecyl sulfate (SDS), a $27 \%$ yield was observed (Table 1, entry 2). Then, the reaction was carried out using the same $3 \% \mathrm{Pd} / \mathrm{C}$ catalyst in the presence of 1.0 eq. and 1.5 eq. of SDS while keeping the other parameters unchanged, but the yields remained almost the same ( $46 \%$ and $47 \%$, respectively) (Table 1 , entries 3 and 4 ). In order to increase the conversion, 1.5 eq. and 2.0 eq. of $\mathrm{K}_{3} \mathrm{PO}_{4}$ were used in the reaction under the same reaction conditions, and $63 \%$ and $89 \%$ yields were found, respectively (Table 1, entries 5 and 6), which shows a sharp improvement in conversion. We then further tried to improve the yields using $15 \mathrm{mg}$ of the catalyst and 2.5 eq. of $\mathrm{K}_{3} \mathrm{PO}_{4}$ under similar conditions, but no further improvement was observed (87\%, Table 1, entry 7$)$. Similar reactions were tried using the $0.5 \%, \mathbf{1 . 0} \%$ and $\mathbf{2} \% \mathrm{Pd} / \mathrm{C}$ catalysts, and the respective yields were found to be $45 \%, 57 \%$ and $76 \%$ (Table 1, entries $8-10$ ). We further tried to optimize 
the reaction time and temperature, and it was observed that a reaction at $100{ }^{\circ} \mathrm{C}$ for $10 \mathrm{~h}$ gave the best results (Table 1, entries 11-15). It is evident from the above findings that the $3 \% \mathrm{Pd} / \mathrm{C}$ catalyst $(10 \mathrm{mg})$ in the presence of 2 eq. of $\mathrm{K}_{3} \mathrm{PO}_{4}$ and 1 eq. of SDS at $100{ }^{\circ} \mathrm{C}$ in $10 \mathrm{~h}$ produced the best conversion.<smiles>C=CC(=O)O</smiles>

acrylic acid $1 \mathrm{mmol}$

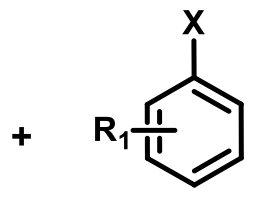

1a-e $1 \mathrm{mmol}$

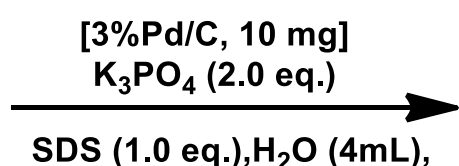

$100^{\circ} \mathrm{C}, 10 \mathrm{~h}$

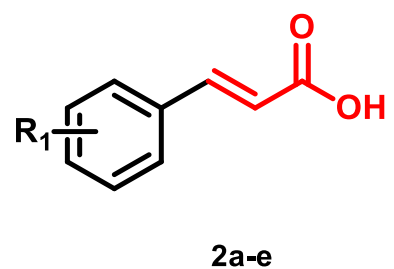

Yield $72-91 \%$

Figure 8. 3\% Pd/C catalyzed Mizoroki-Heck reaction of aryl halides with acrylic acid under optimized conditions.

Therefore, in order to investigate the substrate scope, an $\mathrm{MH}$ cross-coupling reaction was performed under the optimized reaction conditions with several aryl halides and acrylic acid. The results are summarized in Table 2.

Table 2. 3\%Pd/C catalyst Mizoroki-Heck reaction of aryl halides with acrylic acid.

\begin{tabular}{ccccc}
\hline S1. No. & Aryl Halides & 1a-f & 2a-e & Isolated Yield \\
\hline 1 & 4-bromoanisol & $1 \mathrm{a}$ & $2 \mathrm{a}$ & $89 \%$ \\
2 & 3-bromoanisol & $1 \mathrm{~b}$ & $2 \mathrm{~b}$ & $85 \%$ \\
3 & 2-bromoanisol & $1 \mathrm{c}$ & $2 \mathrm{c}$ & $72 \%$ \\
4 & 4-Iodotoluene & $1 \mathrm{~d}$ & $2 \mathrm{~d}$ & $87 \%$ \\
5 & 4-Iodobenzene & $1 \mathrm{e}$ & $2 \mathrm{e}$ & $91 \%$ \\
6 & 4-bromobenzene & 1f & $2 \mathrm{e}$ & $88 \%$ \\
\hline
\end{tabular}

Reaction Conditions: $3 \% \mathrm{Pd} / \mathrm{C}(10 \mathrm{mg}), \mathrm{K}_{3} \mathrm{PO}_{4}(424 \mathrm{mg}, 2 \mathrm{mmol})$, SDS (72 mg, $\left.1 \mathrm{mmol}\right), \mathrm{H}_{2} \mathrm{O}(4 \mathrm{~mL})$, aryl halide $(1.0 \mathrm{mmol})$ and acrylic acid $(1.0 \mathrm{mmol})$ at $100{ }^{\circ} \mathrm{C}$ for $10 \mathrm{~h}$ (isolated yields).

The turnover frequency (TOF) and turnover number (TON) values for the 3\% Pd/C catalyst were calculated and are graphically illustrated in Figure 9. It was found that the TOF and TON values for the Suzuki coupling reaction were 118 and $20 \mathrm{~h}^{-1}$. For the Heck coupling, the TOF and TON values were 1.2 and $12 \mathrm{~h}^{-1}$.
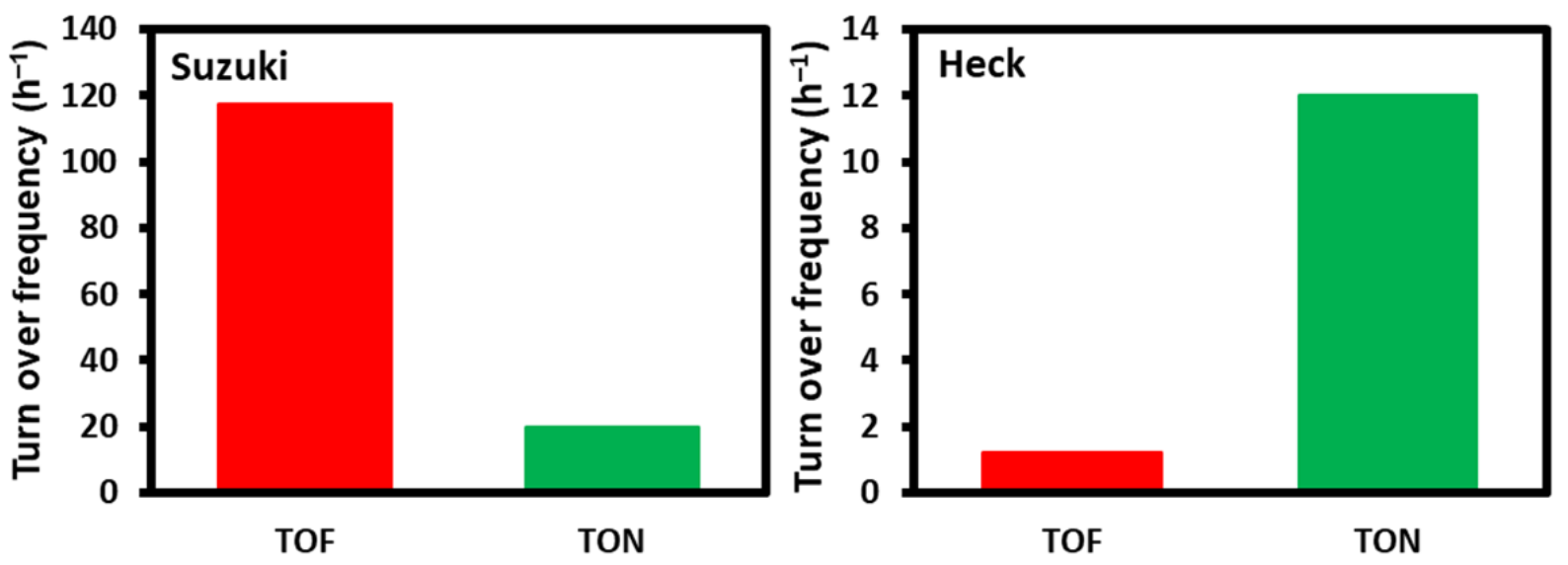

Figure 9. Graphical illustration of the comparative turnover frequency and turnover number (TON) values for the Suzuki and Heck coupling reactions of the $3 \% \mathrm{Pd} / \mathrm{C}$ catalyst.

Under the optimized reaction conditions, all the aryl halides (1a-f) reacted with the acrylic acid very well, with moderate to good yields (Table 2). The lower yield in the case of 2-bromoanisol could be due to the steric hindrance of the ortho-substitution $(2 \mathrm{c}, \mathbf{7 2} \%)$ of 
bromoanisol. The highest yields were observed for iodobenzene (2e, 91\%) and iodotoluene (2d, $\mathbf{8 7 \%}$ ). The reusability of the $3 \% \mathrm{Pd} / \mathrm{C}$ catalysts was tested for Mizoroki-Heck reaction efficiency. The reactions were done in a similar approach to the above-mentioned process. Using a standard $p$-bromoanisol substrate and acrylic acid, the residual catalyst was collected by filtration after the completion of the reaction. The catalyst was washed with copious amounts of water to eliminate any residual impurities. It was found that there was a decrease in the percentage of product formed upon repeated use. The product percentage depreciated up to $78 \%$ when used up to 3 times (Figure 10).

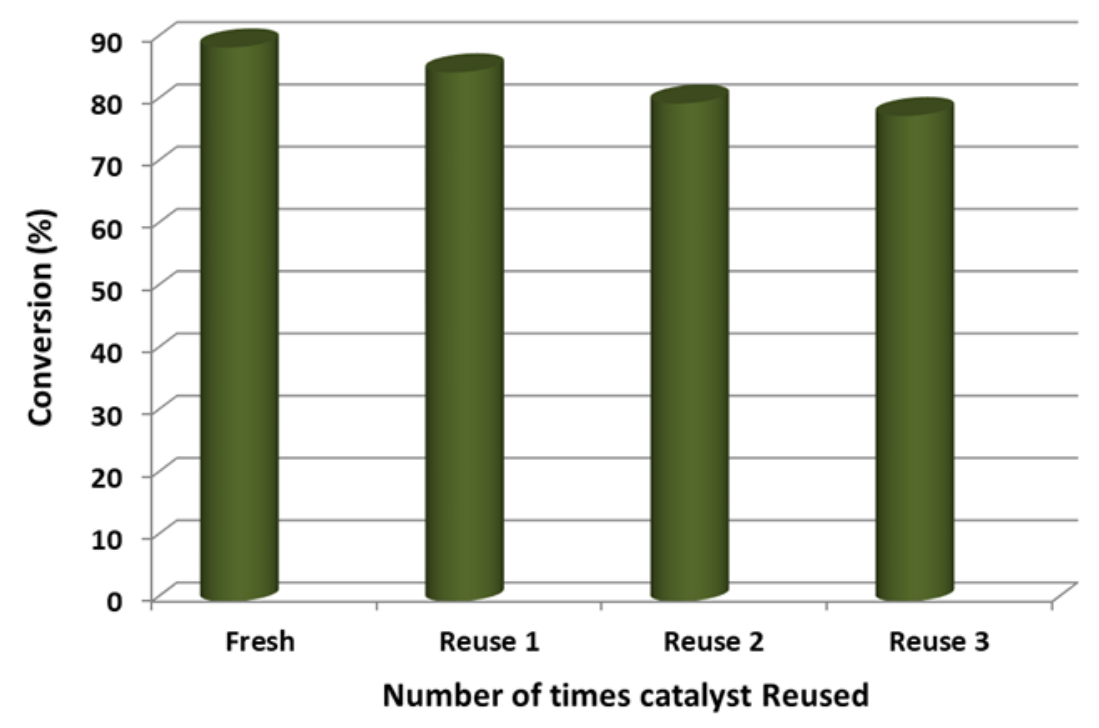

Figure 10. Recyclability studies for the Pd/C 3\% catalyst, using $p$-bromoanisol as the main reactant for the Mizoroki-Heck reaction.

\section{Conclusions}

A Pd/C catalyst was synthesized via an in situ synthesis method, using hydrogen gas as a reducing agent. The incorporation of 'Pd' nanoparticles on the surface of active carbon led to strong catalytic activity of the resultant catalyst. To examine the effect of the amount of 'Pd' on the catalytic activity of the catalyst, various catalysts were prepared by varying the palladium content. The as-prepared catalysts were identified by XRD, SEM, EDX and BET. The Pd/C catalyst containing 3\% Pd demonstrated excellent catalytic activity toward the Suzuki-Miyaura and Mizoroki-Heck reactions. Moreover, the catalyst's reusability was also verified by repeated execution of the same reaction using the reused catalyst. The $3 \% \mathrm{Pd} / \mathrm{C}$ catalyst showed exceptional reusability even after numerous reactions.

Supplementary Materials: The following are available online at https:/ / www.mdpi.com/article/10 .3390 /app11114822/s1. Figure S1: ${ }^{1} \mathrm{H}-\mathrm{NMR}$ of Compound 2a, Figure S2: ${ }^{13} \mathrm{C}-\mathrm{NMR}$ of Compound 2a, Figure S3: ${ }^{1} \mathrm{H}-\mathrm{NMR}$ of Compound $\mathbf{2 b}$, Figure S4: ${ }^{13} \mathrm{C}-\mathrm{NMR}$ of Compound 2b, Figure S5: ${ }^{1} \mathrm{H}-\mathrm{NMR}$ of Compound 2c, Figure S6: ${ }^{13} \mathrm{C}-\mathrm{NMR}$ of Compound 2c, Figure S7: ${ }^{1} \mathrm{H}-\mathrm{NMR}$ of Compound 2d, Figure S8: ${ }^{13} \mathrm{C}-\mathrm{NMR}$ of Compound 2d, Figure S9: ${ }^{1} \mathrm{H}-\mathrm{NMR}$ of Compound 2e, Figure S10: ${ }^{13} \mathrm{C}-\mathrm{NMR}$ of Compound 2e.

Author Contributions: Conceptualization, H.M.A., O.F.A., M.H.A., S.F.A. and M.R.S.; methodology, H.M.A. and M.K.; software, M.R.S.; validation, O.F.A., S.F.A. and M.R.S.; formal analysis, M.H.A., R.L.A., M.S.A., M.H.M., M.S.I. and M.K.; investigation, S.F.A. and M.R.S.; resources, H.M.A., O.F.A., S.F.A. and M.R.S.; data curation, M.R.S.; writing—original draft preparation, O.F.A., S.F.A. and M.R.S.; writing-review and editing, S.F.A. and M.R.S.; visualization, O.F.A., M.H.A., S.F.A. and M.R.S.; supervision, A.A.; project administration, O.F.A.; funding acquisition, A.A. All authors have read and agreed to the published version of the manuscript.

Funding: O.F.A. extends his appreciation to the Deanship of Scientific Research at Majmaah University for funding this research (Grant No. R-2021-135). 
Institutional Review Board Statement: Not applicable.

Informed Consent Statement: Not applicable.

Data Availability Statement: Data are contained within the article or Supplementary Materials.

Conflicts of Interest: The authors declare no conflict of interest.

\section{References}

1. Suzuki, A. Organoboron compounds in new synthetic reactions. Pure Appl. Chem. 1985, 57, 1749-1758. [CrossRef]

2. Heck, R.F. Palladium-catalyzed vinylation of organic halides. Org. React. 2004, 27, 345-390.

3. Milstein, D.; Stille, J. Palladium-catalyzed coupling of tetraorganotin compounds with aryl and benzyl halides. Synthetic utility and mechanism. J. Am. Chem. Soc. 1979, 101, 4992-4998. [CrossRef]

4. Negishi, E. Palladium-or nickel-catalyzed cross coupling. A new selective method for carbon-carbon bond formation. Acc. Chem. Res. 1982, 15, 340-348. [CrossRef]

5. Nakao, Y.; Hiyama, T. Silicon-based cross-coupling reaction: An environmentally benign version. Chem. Soc. Rev. 2011, 40, 4893-4901. [CrossRef] [PubMed]

6. Chinchilla, R.; Nájera, C. Recent advances in Sonogashira reactions. Chem. Soc. Rev. 2011, 40, 5084-5121. [CrossRef]

7. Handa, S.; Wang, Y.; Gallou, F.; Lipshutz, B.H. Sustainable Fe-ppm Pd nanoparticle catalysis of Suzuki-Miyaura cross-couplings in water. Science 2015, 349, 1087-1091. [CrossRef]

8. Yokoyama, A.; Suzuki, H.; Kubota, Y.; Ohuchi, K.; Higashimura, H.; Yokozawa, T. Chain-growth polymerization for the synthesis of polyfluorene via suzuki-miyaura coupling reaction from an externally added initiator unit. J. Am. Chem. Soc. 2007, 129, 7236-7237. [CrossRef]

9. Heravi, M.M.; Hashemi, E. Recent applications of the Suzuki reaction in total synthesis. Tetrahedron 2012, 68, 9145-9178. [CrossRef]

10. Kuniyil, M.; Kumar, J.; Adil, S.F.; Shaik, M.R.; Khan, M.; Assal, M.E.; Siddiqui, M.R.H.; Al-Warthan, A. One-Pot synthesized Pd@ N-doped graphene: An efficient catalyst for suzuki-miyaura couplings. Catalysts 2019, 9, 469. [CrossRef]

11. Nasrollahzadeh, M.; Sajadi, S.M.; Maham, M. Green synthesis of palladium nanoparticles using Hippophae rhamnoides Linn leaf extract and their catalytic activity for the Suzuki-Miyaura coupling in water. J. Mol. Catal. A Chem. 2015, 396, 297-303. [CrossRef]

12. Ocansey, E.; Darkwa, J.; Makhubela, B.C. Synthesis, characterization and evaluation of bulky bis (pyrazolyl) palladium complexes in Suzuki-Miyaura cross-coupling reactions. RSC Adv. 2018, 8, 13826-13834. [CrossRef]

13. Wolf, C.; Xu, H. Efficient synthesis of sterically crowded biaryls by palladium-phosphinous acid-catalyzed cross-coupling of aryl halides and aryl grignards. J. Org. Chem. 2008, 73, 162-167. [CrossRef] [PubMed]

14. Tobisu, M.; Xu, T.; Shimasaki, T.; Chatani, N. Nickel-catalyzed Suzuki-Miyaura reaction of aryl fluorides. J. Am. Chem. Soc. 2011, 133, 19505-19511. [CrossRef] [PubMed]

15. Meise, M.; Haag, R. A highly active water-soluble cross-coupling catalyst based on dendritic polyglycerol n-heterocyclic carbene palladium complexes. ChemSusChem Chem. Sustain. Energy Mater. 2008, 1, 637-642. [CrossRef] [PubMed]

16. Doucet, H.; Hierso, J.-C. Palladium coupling catalysts for pharmaceutical applications. Curr. Opin. Drug Dis. Dev. 2007, 10, 672-690.

17. King, A.O.; Yasuda, N. Palladium-catalyzed cross-coupling reactions in the synthesis of pharmaceuticals. In Organometallics in Process Chemistry; Springer: Berlin/Heidelberg, Germany, 2004; pp. 205-245.

18. Torborg, C.; Beller, M. Recent applications of palladium-catalyzed coupling reactions in the pharmaceutical, agrochemical, and fine chemical industries. Adv. Synth. Catal. 2009, 351, 3027-3043. [CrossRef]

19. Scheuermann, G.M.; Rumi, L.; Steurer, P.; Bannwarth, W.; Mülhaupt, R. Palladium nanoparticles on graphite oxide and its functionalized graphene derivatives as highly active catalysts for the Suzuki-Miyaura coupling reaction. J. Am. Chem. Soc. 2009, 131, 8262-8270. [CrossRef]

20. Mpungose, P.P.; Vundla, Z.P.; Maguire, G.E.; Friedrich, H.B. The current status of heterogeneous palladium catalysed Heck and Suzuki cross-coupling reactions. Molecules 2018, 23, 1676. [CrossRef]

21. Pérez-Lorenzo, M. Palladium nanoparticles as efficient catalysts for Suzuki cross-coupling reactions. J. Phys. Chem. Lett. 2012, 3, 167-174. [CrossRef]

22. Das, P.; Linert, W. Schiff base-derived homogeneous and heterogeneous palladium catalysts for the Suzuki-Miyaura reaction. Coord. Chem. Rev. 2016, 311, 1-23. [CrossRef]

23. Kim, S.-W.; Kim, M.; Lee, W.Y.; Hyeon, T. Fabrication of hollow palladium spheres and their successful application to the recyclable heterogeneous catalyst for Suzuki coupling reactions. J. Am. Chem. Soc. 2002, 124, 7642-7643. [CrossRef] [PubMed]

24. Sun, J.; Fu, Y.; He, G.; Sun, X.; Wang, X. Green Suzuki-Miyaura coupling reaction catalyzed by palladium nanoparticles supported on graphitic carbon nitride. Appl. Catal. B Environ. 2015, 165, 661-667. [CrossRef]

25. Veerakumar, P.; Thanasekaran, P.; Lu, K.-L.; Liu, S.-B.; Rajagopal, S. Functionalized silica matrices and palladium: A versatile heterogeneous catalyst for Suzuki, Heck, and Sonogashira reactions. ACS Sustain. Chem. Eng. 2017, 5, 6357-6376. [CrossRef]

26. Astakhov, A.V.; Khazipov, O.V.; Chernenko, A.Y.; Pasyukov, D.V.; Kashin, A.S.; Gordeev, E.G.; Khrustalev, V.N.; Chernyshev, V.M.; Ananikov, V.P. A new mode of operation of Pd-NHC systems studied in a catalytic Mizoroki-Heck reaction. Organometallics 2017, 36, 1981-1992. [CrossRef] 
27. Bej, A.; Ghosh, K.; Sarkar, A.; Knight, D.W. Palladium nanoparticles in the catalysis of coupling reactions. RSC Adv. 2016, 6, 11446-11453. [CrossRef]

28. Khan, M.; Kuniyil, M.; Shaik, M.; Khan, M.; Adil, S.; Al-Warthan, A.; Alkhathlan, H.; Tremel, W.; Tahir, M.; Siddiqui, M. Plant extract mediated eco-friendly synthesis of Pd@ graphene nanocatalyst: An efficient and reusable catalyst for the Suzuki-Miyaura coupling. Catalysts 2017, 7, 20. [CrossRef]

29. Oger, N.; Felpin, F.X. Heterogeneous palladium catalysts for Suzuki-Miyaura coupling reactions involving aryl diazonium salts. Chem CatChem 2016, 8, 1998-2009. [CrossRef]

30. Movahed, S.K.; Dabiri, M.; Bazgir, A. Palladium nanoparticle decorated high nitrogen-doped graphene with high catalytic activity for Suzuki-Miyaura and Ullmann-type coupling reactions in aqueous media. Appl. Catal., A 2014, 488, 265-274. [CrossRef]

31. Asadi, S.; Sedghi, R.; Heravi, M.M. Pd nanoparticles immobilized on supported magnetic GO@ PAMPS as an auspicious catalyst for Suzuki-Miyaura coupling reaction. Catal. Lett. 2017, 147, 2045-2056. [CrossRef]

32. Yoshii, T.; Kuwahara, Y.; Mori, K.; Yamashita, H. Design of Pd-graphene-Au nanorod nanocomposite catalyst for boosting suzuki-miyaura coupling reaction by assistance of surface plasmon resonance. J. Phys. Chem. C 2019, 123, 24575-24583. [CrossRef]

33. Khalili, D.; Banazadeh, A.R.; Etemadi-Davan, E. Palladium stabilized by amino-vinyl silica functionalized magnetic carbon nanotube: Application in suzuki-miyaura and heck-mizoroki coupling reactions. Catal. Lett. 2017, 147, 2674-2687. [CrossRef]

34. Labulo, A.H.; Martincigh, B.S.; Omondi, B.; Nyamori, V.O. Advances in carbon nanotubes as efficacious supports for palladiumcatalysed carbon-carbon cross-coupling reactions. J. Mater. Sci. 2017, 52, 9225-9248. [CrossRef]

35. Lakshminarayana, B.; Mahendar, L.; Ghosal, P.; Satyanarayana, G.; Subrahmanyam, C. Nano-sized Recyclable PdO supported carbon nanostructures for heck reaction: Influence of carbon materials. ChemSelect 2017, 2, 2700-2707. [CrossRef]

36. Chen, X.; Hou, Y.; Wang, H.; Cao, Y.; He, J. Facile deposition of Pd nanoparticles on carbon nanotube microparticles and their catalytic activity for Suzuki coupling reactions. J. Phys. Chem. C 2008, 112, 8172-8176. [CrossRef]

37. Felpin, F.-X. Ten years of adventures with Pd/C catalysts: From reductive processes to coupling reactions. Synlett 2014, 25, 1055-1067. [CrossRef]

38. Cini, E.; Petricci, E.; Taddei, M. Pd/C catalysis under microwave dielectric heating. Catalysts 2017, 7, 89. [CrossRef]

39. Schmidt, B.; Riemer, M. Suzuki-Miyaura coupling of halophenols and phenol boronic acids: Systematic investigation of positional isomer effects and conclusions for the synthesis of phytoalexins from pyrinae. J. Org. Chem. 2014, 79, 4104-4118. [CrossRef]

40. Yuan, Y.-Q.; Guo, S.-R. Remarkably facile Heck reactions in aqueous two-phase system catalyzed by reusable Pd/C under ligand-free conditions. Synth. Commun. 2012, 42, 1059-1069. [CrossRef]

41. Zhou, X.-Y.; Chen, X.; Wang, L.-G. Recycled Pd/C-catalyzed heck reaction of 2-Iodoanilines under ligand-free conditions. Synthesis 2017, 49, 5364-5370. [CrossRef]

42. Seki, M. Practical synthesis of multifunctional compounds through Pd/C-catalyzed coupling reactions. J. Synth. Org. Chem Jpn. 2006, 64, 853-866. [CrossRef]

43. Dighe, M.G.; Lonkar, S.L.; Degani, M.S. Mechanistic insights into palladium leaching in novel Pd/C-catalyzed boron-Heck reaction of arylboronic acid. Synlett 2013, 24, 347-350.

44. Horikoshi, S.; Serpone, N. Role of microwaves in heterogeneous catalytic systems. Catal. Sci. Technol. 2014, 4, 1197-1210. [CrossRef]

45. Hattori, T.; Tsubone, A.; Sawama, Y.; Monguchi, Y.; Sajiki, H. Palladium on carbon-catalyzed Suzuki-Miyaura coupling reaction using an efficient and continuous flow system. Catalysts 2015, 5, 18-25. [CrossRef]

46. García-Suárez, E.J.; Lara, P.; García, A.B.; Ojeda, M.; Luque, R.; Philippot, K. Efficient and recyclable carbon-supported Pd nanocatalysts for the Suzuki-Miyaura reaction in aqueous-based media: Microwave vs. conventional heating. Appl. Catal. A 2013, 468, 59-67. [CrossRef] 